\title{
HYGIENE SANITASI MAKANAN DI PABRIK MIE “TJAP TIGA ANAK” DESA WLAHAR KULON KECAMATAN PATIKRAJA KABUPATEN BANYUMAS TAHUN 2016
}

\author{
Fitri Permanasari ${ }^{1)}$, Budi Triantoro ${ }^{2)}$ \\ Jurusan Kesehatan Lingkungan, Politeknik Kesehatan Kemenkes Semarang, \\ Jl.Raya Baturaden KM 12 Purwokerto, Indonesia
}

\begin{abstract}
Abstrak
Penerapan enam prinsip hygiene sanitasi makanan di pabrik mie cukup baik dengan prosentase 58\%, kualitas mie secara organoleptik sudah baik, hasil pengukuran kandungan boraks diperoleh hasil bahwa mie kering tidak mengandung boraks, kemudian hasil pemeriksaan angka lempeng total masih di bawah batas maksimum cemaran mikroba pada makanan sesuai Peraturan Kepala Badan POM RI NO HK.006.1.52.4011 Tahun 2009. Kesimpulan hygiene sanitasi makanan di pabrik mie belum memenuhi syarat, yang tidak memenuhi syarat, antara lain : tempat penyimpanan bahan makanan, pengolahan makanan dari segi bangunan memerlukan perbaikan, kemudian penjamah makanan tidak berperilaku baik, serta pengangkutan makanan Pengelola pabrik disarankan menambah gudang untuk tempat penyimpanan makanan, membuat ventilasi di ruang produksi, menyediakan alat pelindung diri untuk penjamah makanan, pengangkutan dan penjemuran dijauhkan dari tempat berdebu, petugas kesehatan melakukan pengawasan dan inspeksi sanitasi secara rutin enam bulan sekali.
\end{abstract}

Kata Kunci : Hygiene Sanitasi Makanan Pabrik Mie

\begin{abstract}
Application of six principle of food hygienesanitation in noodles factory are pretty good with precentage $58 \%$, the quality of noodles in organoleptic is good, the measurement result of borax contents obtain result that dry noodles is not containing borax, then the result of plated total number examination still in under the limit of micobial contamination in food according to the rules of chief POM RI agency NO HK.006.1.52.4011 Tahun 2009. The inference of food hygiene sanitation in food factory still not qualify, which are not eligible, such as : the food storage, food processing from terms of buildings still need of repair, then the food handlers do not behave properly, and food carrying. The manager of the factory is recomended to add more warehouse for place to storing the food, make ventilation in the room of production, serve the self safety kit for food checker, carrying and drying are kept away from dusty place, officer of public health departemet controling \& inspection of sanitation routinely every six months.
\end{abstract}

Keywords : : Food Sanitation Hygiene Noodles Factory

\section{PENDAhUluan}

Makanan merupakan salah satu kebutuhan pokok manusia untuk dapat melangsungkan kehidupan selain kebutuhan sandang dan perumahan. Makanan selain mengandung nilai gizi juga merupakan media untuk berkembang biaknya mikroba. Kemungkinan lain masuknya atau adanya bahan berbahaya, seperti : bahan kimia atau bahan lainnya berupa debu, tanah, rambut manusia dapat berpengaruh buruk terhadap kesehatan manusia dalam mengkonsumsi makanan (Depkes RI, 2004).

Pola konsumsi masyarakat dipengaruhi oleh gaya hidup saat ini. Salah satunya adalah mie yang menjadi pilihan sebagai pengganti nasi maupun sebagai selingan. Kini mie telah memasyarakat bagi kalangan mulai dari anakanak hingga lanjut usia. Saat ini berbagai jenis mie banyak dikonsumsi dan dijual di pasaran, antara lain : mie isntan, mie basah maupun mie kering.

1) Email : fitripermana79@gmail.com

2) Email : mutshabira@yahoo.com
Mie kering adalah mie basah yang dikeringkan dengan cara penjemuran di bawah sinar matahari, mie kering mempunyai kadar air rendah, sehingga mempunyai daya simpan yang relatif panjang dan mudah penanganannya. Apabila masyarakat mengkonsumsi mie, maka harus memperhatikan kualitas dari mie tersebut (Astawan, 1999).

Kualitas mie yang baik secara organoleptik, antara lain: tekstur mie yang lembut saat dipegang, bau khas aroma mie, mie mudah patah, sedangakan kualitas mie secara kimia, mie tidak mengandung bahan kimia berbahaya yang tidak boleh digunakan untuk bahan tambahan pangan, seperti : boraks, formalin dan zat pewarna sintetis, dan kualitas mie secara biologi adalah tidak terdapat jamur pada mie tersebut. Kualitas mie yang tidak baik dapat mengganggu kesehatan.

Gangguan kesehatan yang terjadi, karena terlalu banyak mengkonsumsi mie, antara lain : gangguan pada pencernaan, dan dapat menyebabkan 
keracunan. Hal tersebut dapat disebabkan oleh aktifitas bakteri, jamur, dan mikroorganisme lain serta bahan kimia berbahaya yang tidak boleh digunakan sebagai bahan tambahan makanan. Masuknya kontaminan tersebut kedalam mie dapat bersumber dari mie itu sendiri, atau peralatan yang digunakan, tempat pengolahan yang tidak sehat dapat menurunkan derajat kesehatan manusia.

Masalah sanitasi makanan sangat penting, terutama di tempat-tempat umum yang memberikan pelayanan untuk orang banyak mempunyai peranan yang cukup besar dalam mempengaruhi derajat kesehatan. Salah satu upaya untuk meningkatkan pembangunan kesehatan adalah upaya hygiene sanitasi makanan yang mencakup enam prinsip, diantaranya : pemilihan bahan makanan, penyimpanan bahan makanan, pengolahan makanan, penyimpanan makanan, pengangkutan makanan, penyajian makanan (Anwar, dkk, 1998). Selain enam prinsip hygiene sanitasi makanan, pada perusahaan juga diperlukan fasilitas sanitasi makanan.

Fasilitas penunjang dalam mencapai program sanitasi makanan diperlukan beberapa fasilitas diantaranya adalah penyediaan air bersih, sistem pembuangan sampah yang saniter, system pembuangan limbah cair yang saniter serta sistem pengendalian vektor dan binatang penganggu yang saniter. Hal yang cukup penting untuk menunjang keberhasilan program adalah peralatan dan fasilitas yang memadai, penjamah yang terdidik, standar makanan dan peraturan mengenai makanan, serta pengawasan makanan (Mukono, 2006).

Faktor pengawasan makanan sangat penting untuk diperhatikan, apabila tidak diperhatikan dengan baik dapat mengakibatkan keracunan makanan seperti kasus keracunan mie kuning di Batang. Setelah diperiksa ternyata mie kuning mengandung bakteri dan jamur. (Semarang.id)

Berdasarkan pengamatan awal peneliti di Pabrik mie “Tjap Tiga Anak” Desa Wlahar Kulon, Kecamatan Patikraja, Kabupaten Banyumas Tahun 2016 diketahui kemasan mie yang dihasilkan tidak terdapat batas kadaluarsa mie, kondisi lingkungan tempat pengolahan mie kurang baik, karena lantai di tempat produksi tidak tidak bersih, tempat sampah tidak tertutup, pencahayaan yang tidak memenuhi syarat kesehatan, dalam mengolah makanan penjamah tidak menggunakan alat pelindung diri seperti clemek dan sarung tangan.

Berdasarkan masalah diatas peneliti tertarik untuk melakukan penelitian dengan judul “ Hygiene Sanitasi Makanan di Pabrik Mie Tjap Tiga Anak Desa Wlahar Kulon, Kecamatan Patikraja, Kabupaten Banyumas Tahun 2016”.

Tujuan Umum dari penelitian ini adah untuk mengetahui hygiene sanitasi makanan di Pabrik Mie “Tjap Tiga Anak” di Desa Wlahar Kulon, Kecamatan Patikraja, Kabupaten Banyumas.

a. Mendeskripsikan penerapan enam prinsip hygiene sanitasi makanan dalam pembuatan mie di Pabrik Mie “Tjap Tiga Anak” yang meliputi, pemilihan bahan makanan, penyimpanan bahan makanan, pengolahan makanan, penyimpanan makanan, pengangkutan makanan, penyajian makanan.

b. Mendeskripsikan kualitas mie kering secara organoleptik.

c. Mengukur kandungan boraks pada mie kering.

d. Mengukur kualitas mie kering secara mikrobiologi dengan cara pemeriksaan Angka Lempeng Total

\section{METODE PENELITIAN}

Penelitian ini menggunakan metode deskriptif dengan tujuan untuk memperoleh gambaran tentang Hygiene Sanitasi Makanan yang dilakukan dengan pengumpulan data lapangan dan laboratorium yang dianalisis kemudian dibandingkan dengan ketentuan perundang-undangan yang berlaku serta pendapat para ahli dan pendapat penulis. Lokasi penelitian adalah home industri tahu di Kelurahan Kalikabong Kecamatan Kalimanah Kabupaten Purbalingga yang dilakukan pada bulan April 2016 di Pabrik Mie Tjap Tiga Anak Desa Wlahar Kulon Kecamatan Patikraja Kabupaten Banyumas Tahun 2016.

\section{HASIL DAN PEMBAHASAN}

1. Data Umum

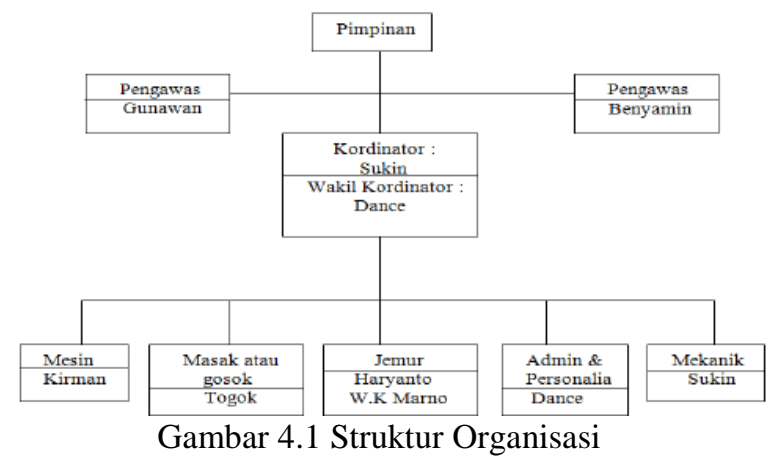

Pabrik Mie Tjap Tiga Anak yang berada di Desa Wlahar Kulon Kecamatan Patikraja Kabupaten Banyumas. Batas wilayah Pabrik Mie adalah sabagai berikut :

- Sebelah Utara : Pemukiman

- Sebelah Timur : Pemakaman Umum

- Sebelah Selatan : Pemukiman

- Sebelah Barat : Pemukiman

Pabrik Mie Tjap Tiga Anak terletak diatas tanah seluas kurang lebih 400 M2 yang dibangun di dekat pemukiman warga. Pabrik ini terdiri dari 4 bangunan, antara lain : bangunan pertama sebagai tempat dari pengawas (kantor). Bangunan kedua sebagai tempat produksi mulai dari pencampuran bahan hingga pengemasan dilakukan dalam satu tempat. Bangunan ketiga merupakan tempat penyimpanan bahan baku berupa tepung terigu, dan bangunan keempat yaitu sebagai tempat untuk memanaskan mie 
kering setelah dijemur, panas tersebut berasal dari mesin sederhana yang terdapat di luar ruang pengering.

Sejarah Pabrik Mie Kering Tjap Tiga Anak merupakan suatu badan usaha milik perorangan. Pabrik yang memproduksi mie pertama di Banyumas sejak tahun 1925 dan sudah mempunyai nomer ijin usaha 206330210060, pemiliknya adalah Ho Kie San, kemudian diturunkan kepada anaknya yang bernama R. Yusuf Kasantoso, S.H pada tahun 1988 hingga tahun 2005, setelah itu tahun 2005 kepemilikan dipegang oleh Yusak Gunadisantoso hingga saat ini.

Pabrik ini awalnya dibangun di tengah masyarakat kota, tetapi lambat tahun mendapat komplain dari masyarakat sekitar pabrik, hal ini dikarenakan asap pabrik yang keluar dari cerobong asap mencemari lingkungan penduduk sekitar, sehingga pada tahun 2005 Pabrik Mie Kering Tjap Tiga Anak berpindah lokasi di Desa Wlahar Kulon Kecamatan Patikraja Kabupaten Banyumas hingga sampai saat ini.

Pabrik ini tidak memiliki cabang, untuk pemasaran dibedakan menjadi 2 merek, untuk daerah Banyumas menggunakan label Tjap Tiga Anak, sedangkan untuk daerah Magelang menggunakan label Sumpit Mas. Pabrik ini merupakan industri kecil, karena pengolahannya masih menggunakan mesin sederhana dan masih membutuhkan tenaga manusia.

\section{Data Khusus}

a. Hygiene Sanitasi Makanan di Pabrik Mie Tjap Tiga Anak

1) Pemilihan bahan baku

Pemilihan bahan baku yang dilakukan di pabrik ini sudah baik, sehingga masuk kategori memenuhi syarat dengan prosentase $100 \%$, karena bahan yang digunakan berasal dari sumber yang resmi dan diakui, bahan baku dalam kondisi baik, dan tidak kadaluarsa. Bahanbahan yang digunakan untuk pembuatan mie adalah sebagi berikut :

a) Tepung terigu

Tepung terigu dilihat dari kondisi secara fisik tepung terigu berwarna putih kekuningan, tepung tidak terdapat cemaran, dan tidak kadaluarsa, sehingga produk hasil olahannya menjadi baik untuk dikonsumsi. Apabila tepung terigu yang digunakan tidak dalam kondisi yang baik dan sudah kadaluarsa, maka dapat menurunkan kualitas mie yang dihasilkan dan tidak baik untuk dikonsumsi, karena dapat menyebabkan keracunan atau sakit perut.

b) Air

Kondisi air secara fisik tidak berbau, tidak berasa dan tidak bewarna. Untuk itu air tidak menimbulkan bahaya, sehingga dapat meningkatkan kualitas produk.

c) Bahan pewarna

Bahan pewarna yang digunakan sudah benar, karena sudah sesuai dengan persyaratan yang ada tentang bahan tambahan makanan. Bahan tambahan makanan yang tidak boleh digunakan untuk makanan adalah Rhodamin B, Methanil Yellow, dan Tertazine. Sebaiknya pihak pabrik tidak mengganti bahan pewarna yang digunakan dengan menggunakan bahan pewarna yang tidak diperbolehkan untuk makanan, karena dapat membahayakan kesehatan, seperti : iritasi pada pada saluran pernafasan, iritasi kulit, serta dapat menyebabkan keracunan.

d) Garam

Garam sangat berperan untuk memberikan rasa, akan tetapi mie yang dihasilkan setelah dirasakan tidak asin, hal itu dikarenakan bahwa garam tidak hanya untuk memperkuat rasa pada makanan melainkan dapat mengurangi atau memperlambat pertumbuhan mikroorganisme pada makanan.

e) Bahan pewarna makanan

Bahan pengawet yang digunakan adalah benzoat, hal ini sudah benar karena tidak membahayakan kesehatan dan sudah sesuai dengan persyaratan yang ada. Sebaiknya pihak pabrik tidak mengganti bahan pengawet yang digunakan, karena bahan pengawet yang digunakan sekarang sudah benar. Banyak produsen makanan memproduksi makanan dengan menambahkan bahan makanan yang dilarang dipergunakan untuk makanan, seperti boraks dan formalin tanpa memikirkan efek samping. Adapun bahaya boraks dan formalin adalah sebagai berikut : apabila terkena kulit akan menyebabkan kemerahan pada kulit, dapat menyebabkan keracunan dan merusak saraf. 
2) Pengolahan makanan

a) Tempat

1. Lantai

Lantai yang terdapat diruang produksi sudah baik dengan prosentase $80 \%$. Lantai di ruang produksi terbuat dari bahan yang kuat (diplester), tidak licin, mudah dibersihkan, dan kedap air tetapi kondisi lantai tidak bersih, sebaiknya pihak pabrik memberitahukan kepada para pekerja untuk tetap menjaga kebersihan selama proses produksi sedang berlangsung agar tidak terdapat debu, karena debu sangat mudah tertiup oleh angin, sehingga dapat mencemari mie yang dihasilkan, dan makanan yang tercemar dapat menyebabkan sakit perut.

2. Dinding

Dinding yang terdapat di ruang produksi kurang baik dengan prosentase $50 \%$, item yang tidak memenuhi syarat adalah warna dinding tidak terang dan kotor, sedangkan item yang memenuhi syarat adalah dinding kedap air dan rata. Sebaiknya pihak pabrik melakukan perbaikan dengan cara mengecat ulang dinding dan memberitahukan kepada pekerja untuk menjaga kebersihan dinding, karena dinding yang bersih dan berwarna terang dapat membuat pekerja nyaman saat bekerja kemudian ruangan tidak membosankan, sehingga dapat meningkatkan produkstifitas pekerja.

3. Atap

Atap yang terdapat di pabrik sudah cukup baik dengan prosentase $66 \%$, item yang tidak memenuhi syarat adalah atap tidak mudah untuk dibersihkan, kemudian tidak rapat serangga tikus. Hal yang harus dilakukan oleh pihak pabrik adalah membuat langitlangit yang rapat serangga dan tikus agar mudah dibersihkan sehingga tidak terdapat debu dan sarang laba-laba serta tidak terjadi kontaminasi pada pada produk mie.

4. Ventilasi

Hasil pengamatan dengan menggunakan checklist menunjukkan bahwa pada ruang produksi tidak terdapat ventilasi, hal itu dapat membuat pekerja tidak mendapat udara segar dan merasa panas saat berada didalam ruang produksi, untuk itu pihak pabrik perlu berdiskusi dengan pemilik pabrik untuk membuat ventilasi pada ruang produksi dengan jumlah yang cukup agar udara segar selalu mengalir di ruangan produksi, sehingga karyawan tidak merasa panas saat berada di dalam ruangan dan dapat meningkatkan produktifitas pekerja.

b) Penjamah makanan

Hasil pengamatan terhadap penjamah makanan di Pabrik Mie dengan menggunakan cheklist menunjukkan bahwa penjamah tidak baik, sehingga tidak memenuhi syarat personal hygiene yang baik dengan prosentase $20 \%$, karena pada saat mengolah makanan diketahui penjamah makanan mengobrol ketika proses produksi sedang berlangsung, merokok, tidak mencuci tangan ketika sebelum ataupun sesudah bekerja, dan tidak menutup mulut ketika bersin atau batuk, hal itu dapat membuat makanan menjadi terkontaminasi akibat perilaku pekerja yang tidak baik ketika mengolah mie. Sebaiknya pihak pabrik bekerja sama dengan Dinas Kesehatan atau Puskesmas untuk memberikan penyuluhan kepada pekerja dan menyediakan alat pelindung diri, seperti : masker, sarung tangan, clemek dan penutup kepala untuk mengurangi atau mencegah kontaminasi makanan yang disebabkan oleh penjamah makanan, sehingga tidak terjadi penularan penyakit melalui makanan.

c) Peralatan masak

Peralatan masak yang digunakan oleh pabrik ini sudah cukup baik dengan prosentase $66 \%$, karena 
alat yang digunakan menggunakan mesin jaman dahulu sehingga pemakaiannya sudah lama dan mesinnya menjadi berkarat. Pihak pabrik harus memberitahukan kepada pekerja untuk melakukan perawatan terhadap mesin yang digunakan dengan cara memberikan minyak ke dalam bagian mesin agar mesin tidak mudah berkarat kemudian tidak mencemari dan mengkontaminasi produk mie yang dihasilkan, sehingga mie tetap aman untuk dikonsumsi.

d) Sarana sanitasi

1. Tempat sampah

Tempat sampah yang terdapat di pabrik ini cukup baik dengan prosentase 60\%, karena tempat sampah yang tersedia tidak tertutup dan tidak mudah dijangkau, hal ini dapat menyebabkan bau dan pekerja susah untuk membuang sampah sehingga membuat pekerja membuang sampah sembarangan di dalam ruang produksi. Pihak pabrik hendaknya menyediakan tempat sampah yang tertutup agar bau sampah tidak mengganggu dan mencemari lingkungan pabrik, kemudian meletakan tempat sampah di tempat penghasil samah khususnya didalam ruang produksi. Sehingga ruangan tetap bersih, sampah tidak berserakan dan tidak dihinggapi lalat, karena lalat dapat mengkontaminasi makanan, makanan yang terkontaminasi dapat menyebabkan makanan menjadi tidak sehat.

2. Tempat cuci tangan

Cuci tangan di pabrik sudah baik dengan prosentase $50 \%$, karena tempat cuci tangan tidak mudah dijangkau, sehingga menyebabkan pekerja malas untuk mencuci tangan ketika sebelum ataupun sesudah bekerja. Pihak pabrik sebaiknya meletakan tempat cuci tangan dekat dengan tempat produksi dan menambahkan gambar tentang 7 langkah cuci tangan yang baik dengan tujuan agar pekerja mengerti dan mengubah cara cuci tangan mereka yang kurang baik menjadi baik, sehingga tangan pekerja menjadi bersih, karena tangan yang bersih dapat mengurangi cemaran mikroba yang disebabkan oleh tangan penjamah.

3. Saluran air limbah

Saluran air limbah sudah cukup baik dengan prosentase 66\%, karena saluran air limbah yang terdapat di pabrik tidak tertutup. Untuk itu pihak pabrik perlu memperbaiki saluran air limbah dibuat menjadi tertutup agar baunya tidak mencemari lingkungan pabrik.

3) Pengangkutan makanan

Pengangkutan di pabrik ini tidak baik, sehingga tidak memenuhi syarat dengan prosentase 25\%, karena tidak sesuai dengan cara pengangkutan yang baik, seperti : peralatan yang digunakan untuk mengangkut harus tertutup, jalur yang digunakan untuk mengangkut makanan tidak melewati sumber pencemaran, dan tenaga pengangkut mempunyai personal hygiene yang baik, sebaiknya pihak pabrik bekerja sama dengan Dinas Kesehatan untuk memberikan penyuluhan 6 prinsip hygiene sanitasi kepada pekerja, sehingga pekerja mengerti tentang cara pengangkutan yang baik. Pengangkutan yang kuran baik dapat menyebabkan makanan terkontaminasi dengan lingkungan sekitar selama proses pengangkutan berlangsung.

4) Penyimpanan makanan jadi

Penyimpanan makanan jadi tidak baik, sehingga masuk kategori tidak memenuhi syarat dengan prosentase $25 \%$, item yang tidak memenuhi syarat antara lain : tempat penyimpanan makanan tidak bersih, tempat penyimpanan masih campur dengan tempat penyimpanan bahan baku serta pengolahan makanan, kemudian ruangan tidak rapat serangga dan tikus. Hal yang perlu diperhatikan agar penyimpanan menjadi baik adalah menyediakan tempat khusus untuk penyimpan makanan yang sudah jadi dan dibuat rapat serangga, sehingga 
mie tidak terkontaminasi oleh serangga dan tikus serta tidak mudah rusak.

5) Penyajian atau pengemasan makanan Pengemasan yang dilakukan di pabrik ini sudah baik, sehingga memenuhi syarat dengan prosentase $80 \%$, karena sudah sesuai dengan persyaratan yang ada, sehingga produk tetap aman untuk dipasarkan kepada masyarakat. Persyaratan pengemasan yang baik diantaranya adalah : kemasan tidak rusak, kedap air, tahan panas, terdapat label dan merek.

b. Kualitas Mie Secara Organoleptik

Kualitas makanan secara organoleptik dengan menggunakan indera manusia dan cheklist ternyat kondisi mie secara fisik adalah mie yang dihasilkan berbau aroma khas mie, rasa tidak tengik dan bewarna kuning keputihan, hal ini menunjukkan bahwa mie yang diproduksi tidak menggunakan bahan pewarna berbahaya, sehingga mie layak untuk dikonsumsi, karena kualitas mie sudah sudah baik sesuai dengan persyaratan yang ada, untuk itu pihak pabrik tetap harus menjaga kualitas agar lebih baik lagi. Ciri-ciri mie yang baik adalah : keadaan bau, warna, dan rasa secara fisik dalam kondisi yang normal.

c. Kualitas Makanan Secara Kimia

Pemeriksaan parameter kualitas makanan secara kimia dengan cara pemeriksaan kandungan boraks pada mie di Laboratorium Kesehatan Masyarakat Kabupaten Banyumas. Hasil pemeriksaan menunjukkan bahwa sampel mie yang diperiksa negatif mengandung boraks, sehingga mie aman untuk dikonsumsi, karena tidak mengandung bahan pengawet berbahaya yang dapat membhayakan kesehatan.

d. Kualitas Makanan Secara Mikrobiologi

Kualitas makanan secara mikrobiologi dengan cara pemeriksaan Angka Lempeng Total (ALT) pada produk mie kering sebanyak 3 sampel, pemeriksaan dilaksanakan di Laboratorium Kesehatan Lingkungan Kampus 7 Purwokerto. Berdasarkan hasil pemeriksaan diperolahe hasil mkiroba berwarna kuning mengkilap, menurut pembimbing Laboratorium pada saat pengemasan dilakukan sambil mengobrol. Hasil Pemeriksaan ALT adalah sebagai berikut :

Tabel 5.1 Kualitas Makanan Secara Mikrobilogi

\begin{tabular}{|c|c|c|c|c|c|}
\hline $\begin{array}{l}\mathrm{N} \\
\mathrm{o} .\end{array}$ & $\begin{array}{c}\text { Kode } \\
\text { Sampe } \\
1\end{array}$ & I ml & $0,1 \mathrm{ml}$ & $\begin{array}{l}\text { Hasil } \\
\text { Akhir }\end{array}$ & Standar \\
\hline 1. & $\mathrm{~A}$ & 960 & 88 & 92.000 & \multirow{3}{*}{$\begin{array}{c}1 \times 10^{-6} \mathrm{kol} / \mathrm{kg} \\
\text { BPOM } 2009\end{array}$} \\
\hline 2. & B & 1936 & 200 & 196.800 & \\
\hline 3. & C & 22 & 0 & 1.100 & \\
\hline
\end{tabular}

Berdasarkan Peraturan Kepala Badan POM RI NO HK.006.1.52.4011 Tahun 2009 tentang penetapan batas cemaran maksimum mikroba dalam makanan masih memenuhi syarat, karena hasil yang diperoleh masih dibawah batas maksimum 106 (1.000.000) mikroba, akan tetapi pihak industri harus mengingatkan pekerja untuk tidak mengobrol ketika proses produksi sedang berlangsung terutama pada saat pengemasan dengan maksud untuk mengurangi cemaran mikroba pada mie kering.

\section{KESIMPULAN DAN SARAN}

1. Kesimpulan

a. Penerapan enam prinsip hygiene sanitasi makanan di Pabrik Mie Tjap Tiga Anak diperoleh hasil cukup baik dengan prosentase $58 \%$ dikategorikan tidak memenuhi syarat, yang tidak memenuhi syarat antara lain : tempat penyimpanan makanan belum terpisah dengan tempat penyimpanan bahan dan ruang pengolahan makanan, pengolahan makanan dilihat dari kondisi bangunan ruang pengolahan makanan memerlukan perbaikan seperti pemberian ventilasi didalam ruang produksi, penjamah makanan tidak berperilaku baik, serta pengangkutan makanan dekat dengan tempat yang berdebu.

b. Kualitas Mie Kering secara organoleptic baik, karena keadaan bau, warna, dan rasa secara fisik dalam kondisi yang normal.

c. Hasil pemeriksaan Boraks pada sampel mie kering didapatkan hasil bahwa mie kering tidak mengandung boraks.

d. Berdasarkan hasil pengukuran mikrobiologi dengan cara pemeriksaan angka lempeng total didapatkan hasil masih dibawah batas maksimum cemaran mikroba yang ditetapkan oleh Kepala Badan POM Tahun 2009 adalah 106 (1.000.000) mikroba.

2. Saran

a. Pihak pengelola

1) Menambah 1 gedung untuk tempat penyimpanan makanan, penanggung jawab pabrik memberitahukan kepada pekerja untuk tetap menjaga kebersihan selama proses produksi berlangsung agar mie yang diproduksi tidak 
tercemar oleh debu, penanggung jawab menyediakan ventilasi di ruang produksi. Agar udara segar selalu mengalir diruangan pengolahan.

2) Pihak pabrik sebaiknya menyediakan alat pelindung diri kepada pekerja seperti : sarung tangan plastik, masker, clemek dan tutup kepala, selain itu pihak pabrik perlu bekerja sama dengan Dinas Kesehatan atau Puskesmas untuk memberikan penyuluhan kepada pekerja akan pentingnya personal hygiene penjamah makanan.

3) Saat pengangkutan makanan dan penjemuran dijauhkan dari tempat yang berdebu.

4) Disediakan prosedur cara cuci tangan yang baik untuk mengubah kebiasaan cuci tangan pekerja agar lebih baik.

5) Membersihkan langit-langit secara rutin.

b. Dinas Kesehatan dan Puskesmas

1) Sebaiknya pihak Dinas Kesehatan Kabupaten Banyumas melakukan pengawasan dan inspeksi sanitasi secara rutin enam bulan sekali.

2) Memberikan peringatan atau teguran kepada pengelola pabrik, apabila melanggar aturan yang sudah ditetapkan Dinas Kesehatan Kabupaten dapat mencabut ijin usaha apabila setelah diperingatkan tetap melanggar.

\section{DAFTAR PUSTAKA}

Catur Indah Oktaliasari, 2009, Studi Tentang Hygiene Sanitasi Pembuatan Dan Kualitas Mikrobiologi Jenang Salak di Desa Bantarwuru Kecamatan Madukura Kabupaten Banjarnegara Tahun 2009, KTI, Purwokerto : Politeknik Kesehatan Semarang.

Departemen Kesehatan 1989. Anwar, dkk, 1989 Tentang Sanitasi Makanan dan Minuman pada Institusi Pendidikan Tenaga Sanitasi, Jakarta.

Ditjen PMM \& PLP, 1998, Pedoman Pembinaan dan Pengawasan Sanitasi Makanan, Jakarta, Depkes RI.

Farah Tifani, 2013, Study Hygiene Sanitasi Pembuatan Souhun PT Naga Sakti Kecamatan Sumbang Kabupaten Banyumas Tahun 2013, KTI, Purwokerto : Politeknik Kesehatan Semarang.
Imrotul Istiqomah, 2008, Study Hygiene Sanitasi Tempat Pembuatan Cucur di Kelurahan Pasar Batang Kecamatan Brebes Kabupaten Brebes Tahun 2008, KTI, Purwokerto : Politeknik Kesehatan Semarang.

Keputusan Menteri Kesehatan 1990. Keputusan Menteri Kesehatan Republik Indonesia Nomor 416/MENKES/SK/IX/1990 tentang Persyaratan Baku Mutu Air Bersih. Keputusan Menteri Kesehatan 2003. Keputusan Menteri Kesehatan Republik Indonesia Nomor 715/MENKES/SK/VII/2003 tentang Persyaratan Hygiene Sanitasi Jasa Boga.

Keputusan Menteri Kesehatan 1998. Keputusan Menteri Kesehatan Republik Indonesia Nomer 722/MENKES/SK/IX/1998 tentang Bahan Tambahan Pangan. Keputusan Menteri Kesehatan 2003.

Keputusan Menteri Kesehatan Republik Indonesia Nomer 942/MENKES/SK/VII/2003 tentang Persyaratan Hygiene Sanitasi Makanan Jajanan

Keputusan Menteri Kesehatan 2003. Keputusan Menteri Kesehatan Republik Indonesia Nomor 1908/MENKES/SK/VII/2003 tentang Persyaratan Hygiene Sanitasi Rumah Makan dan Restoran.

Keputusan Menteri Kesehatan 2011. Keputusan Menteri Kesehatan Republik Indonesia Nomor 1096/MENKES/PER/VI/2011 tentang Hygiene Sanitasi Jasa Boga.

Peraturan Kepala Badan Pengawas Obat dan Makanan Nomor HK.00.06.1.52.4011 Tahun 2009, Penetapan Batas Maksimum Cemaran Mikroba Dan Kimia Dalam Makanan, Jakarta.

Peraturan Pemerintah 2004. Peraturan Pemerintah Republik Indonesia Nomor 28 Tahun 2004 tentang Keamanan, Mutu dan Gizi Pangan.

Standar Nasional Indonesia, 1996, Mie Kering, Jakarta: Badan Standarisasi Nasional.

Tri Cahyono, 2014, Pedoman Penulisan Proposal Penelitian dan Karya Tulis Ilmiah/Skripsi (Edisi Revisi Ketiga), Purwokerto; Kementerian Kesehatan RI Politeknik Kesehatan Kementerian Kesehatan Semarang. 